\title{
DESENVOLVIMENTO SUSTENTÁVEL E O USO DA ÁGUA NA REGIÃO NORDESTE DO BRASIL
}

Maíra Caroline Carloto Lopes - mairacarlto@ gmail.com Instituto Federal do Ceará, Campus Maracanaú

Bianca Bezerra do Real - biancabezerra06@gmail.com

Instituto Federal do Ceará, Campus Maracanaú

Felipe Nicolas de Morais Garcia - felipenicolasmg@gmail.com

Instituto Federal do Ceará, Campus Maracanaú 


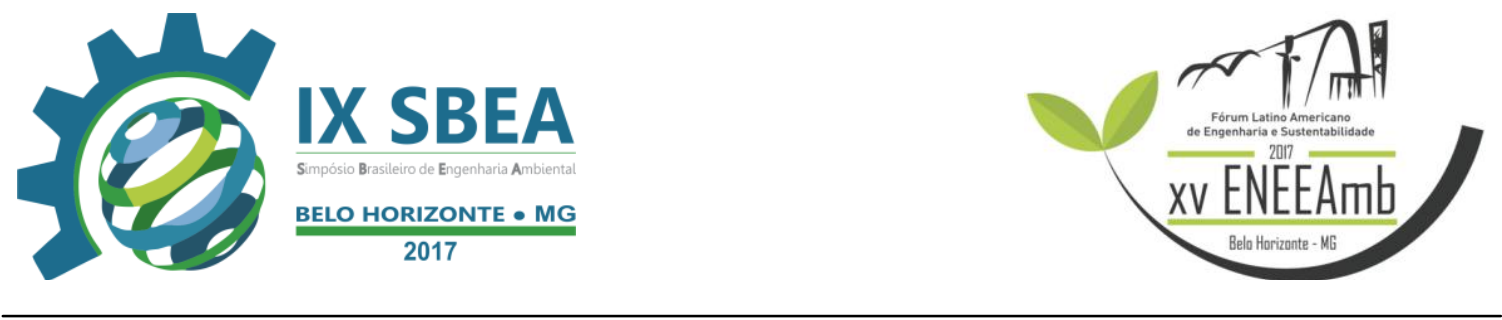

\section{RESUMO}

Este trabalho trata-se de uma pesquisa feita através de levantamentos de dados sobre a problemática da água na região Nordeste, visto que a água é um elemento vital, é purificadora, e é um recurso renovável. Os ciclos de energia biológica, química e física estão todos relacionados com o ciclo da água. Por isso, a opção pelo desenvolvimento sustentável - processo que visa suprir as necessidades da atual geração, sem comprometer a capacidade de fornecer as necessidades das futuras gerações- torna a seca um fato social, além de um fenômeno físico. A origem social dessa problemática pode ser destacada, já que a conduta humana intensifica os efeitos da seca. Além disso, a posição político-científica também é uma questão que influencia na conservação, distribuição e qualidade dos recursos hídricos disponíveis para a sociedade. Portanto, as condições físico-climáticas da região Nordeste podem complicar o bem-estar da população, mas não podem ser unicamente culpadas pelo sofrimento e pobreza nessa área. O padrão cultural e a gestão das organizações públicas e privadas necessitam de um melhor envolvimento nas questões da água.

Palavras- chaves: Recursos hídricos. Desenvolvimento sustentável. Nordeste. Brasil.

\section{INTRODUÇÃO/OBJETIVO}

O uso e disponibilidade da água na região Nordeste do Brasil é um fator crítico que influencia o desenvolvimento dessa área. Grandes ações vêm sendo implantadas com o objetivo de fornecer água para a população e animais. Porém, as crises da água no Brasil, particularmente na região Nordeste, existem políticas seladas que ao instigam o cultivo do problema (ALDO, 1996). Assim, esses procedimentos ainda são incapazes de resolver os problemas decorrentes da escassez de água, fato que torna as populações expostas aos problemas da seca.

De qualquer modo, melhorar e ampliar as estruturas hídricas através de modelos de gerenciamento integrado - ambiental e dos recursos hídricos superficiais e subterrâneos e das concepções de uso e proteção, do usuário pagador, do poluidor pagador- são pré-requisitos para a possível solução do problema. Esperando assim, diminuir as taxas de êxodo rural, além de interiorização de tecnologias e desenvolvimento. 


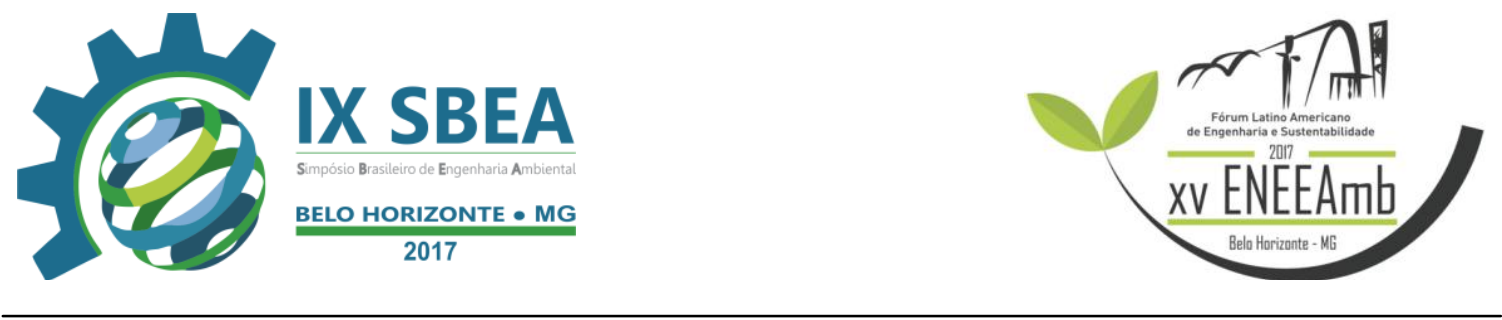

A sustentabilidade hídrica, segundo Carey (1993), corresponde "ao número máximo de usuários e demandas associadas que determinado ambiente pode prover de forma permanente". Por isso, ao usar e implantar políticas para desenvolver recursos hídricos de uma determinada é essencial priorizar as necessidades básicas e de proteção ao meio ambiente. As relevâncias dessas tarefas possuem resultados socioeconômicos óbvios, cujo alcance é mundial (ALDO,1996).

Os principais fatores analisados que contribuem para a crise da água no Nordeste brasileiro são: aumento da demanda, degradação da qualidade dos recursos hídricos nos mananciais, baixa eficácia do saneamento básico e métodos de irrigação ineficazes na agricultura (IBAM,1993). Portanto, conhecer e analisar os principais problemas existentes na região é de suma importância para que seja encontrada uma possível solução para a problemática.

\section{METODOLOGIA}

Os dados e números da temática abordada foram obtidos através de pesquisas em artigos científicos, monografias, dissertações e consultas em sites de instituições federais, estaduais e privadas.

\section{RESULTADOS E DISCUSSÃO}

\subsection{Desperdício e Escassez (crise)}

Em IV a.C. Aristóteles, assinalou algumas condições essenciais para que haja vida, essas seriam, terra, ar, água e o calor. "Terra e ar existem em todos os lugares e com qualidade propícia à vida em geral. Restam água e calor: se falta um ou outro, a vida desaparece". Essas condições são encontradas em todo o país, principalmente na região Nordeste (ALDO, 1996). Sobre mais de 90\% do território brasileiro ocorre precipitações anuais entre $1000 \mathrm{~mm}$ e $3000 \mathrm{~mm}$ e somente na região nordeste concentrase uma média entre 300 e $800 \mathrm{~mm}$ anual. Em termos de temperatura médias anuais ficam entre 17C e 27C. Mesmo possuindo todas essas peculiaridades, o Nordeste brasileiro vem enfrentando uma preocupante crise hidrológica, no que envolve escassez e desperdício.

Um dos pontos preocupantes, está relacionado com a descarga dos rios brasileiros, principalmente os localizados na região Nordeste. O território brasileiro 


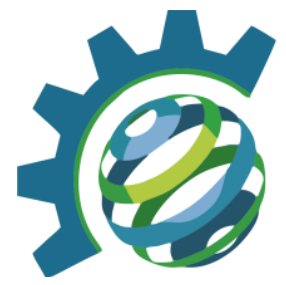

possui uma das redes hidrográficas mais extensas do mundo, cuja descarga anual são de $5619 \mathrm{~km} 3$, representando $14 \%$ da descarga mundial que é de $41 \mathrm{mil} \mathrm{km3} \mathrm{(WRI,1990).}$ Com essa descarga média anual, os rios brasileiros conseguem ofertar 38 mil m3/hab/ano para atendimento de uma demanda total média ordem de $300 \mathrm{~m} 3 / \mathrm{hab} / \mathrm{ano}$.

Mas vale ressaltar que o real significado prático dos valores de deflúvio médio é mascarado pela falta de sintonia existente entre a distribuição desses potenciais e a localização das demandas.

Nesse cenário, conforme os dados do senso de 1990, uma grande parte das descargas nos rios, $80 \%$, ocorrem no nos setores ocupados por somente $5 \%$ da população, os outros $20 \%$ restantes abastecem $95 \%$ do contingente populacional (IBGE, 1991).

Apesar dessa irregularidade na descarga dos rios, a potencial per capita na região nordeste é bastante expressiva de acordo com o estudo utilizando o quociente do volume das descargas médias dos rios (DENAEE, 1985) e população (IBGE, 1991). Tomando como exemplo, um pernambucano (1320 m3/hab/ano) dispõe de mais agua comparado a um alemão (1160 m3/hab/ano); o francês (3030 m3/hab/ano) e o baiano (3028 m3/hab/ano); outro exemplo é o piauiense (9608 m3/hab/ano) que dispõe aproximadamente da mesma quantidade de agua comparado a um americano (9940 m3/hab/ano). Porém, na maioria dos países desenvolvidos o consumo total per capita fica entre 500 e 1000 m3/ano, que corresponde entre 24 e $92 \%$ dos respectivos potenciais e já na região nordeste os consumos per capita são inferiores $10 \%$ dos seus potenciais de água nos rios (Rebouças, 1994).

” Efetivamente, a crise da água no Brasil, especialmente na região Nordeste, resulta da intervenção altamente predatória neste espaço, levando ao efeito perverso de aplicar, a um fenômeno marcadamente estrutural, políticas seladas pela visão conjuntural que induzem ao cultivo do problema" (ALDO, 1996).

Os problemas são um reflexo da falta de gerenciamento efetivo das ações desenvolvimentistas em geral e da água. Há um grande estimulo ao crescimento da industrialização e urbanização em várias áreas que já se tem escassez de água para abastecimento. Em adição, a qualidade da água dos mananciais é degradada pelo 


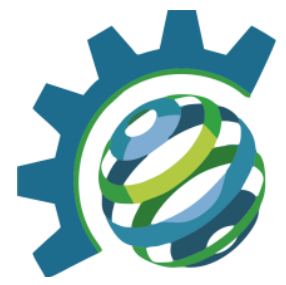

lançamento de esgotos industriais e domésticos não tratados, outros fatores importantes são o uso e a ocupação inadequada do meio físico.

Entre outros fatores que contribuem para a crise da água no Nordeste brasileiro, alguns possuem um destaque, como os citados abaixo:

- De acordo com o IBAM (1993), na região nordeste ocorre um crescimento rápido e desordenado das demandas- apenas 9 regiões metropolitanas possuem uma população de 42,5 milhões de habitantes que é o equivalente a $27 \%$ da população brasileira em 156 municípios, ou $3 \%$ do total;

- Degradação da qualidade dos mananciais cada vez mais acentuada. São observados lançamentos de cerca de $90 \%$ dos esgotos domésticos e $70 \%$ dos esgotos industriais não-tratados e disposição inadequada do lixo produzido. Diariamente são produzidas 241.614 toneladas de lixo no brasil, sendo desse total, 90 mil de lixo domiciliar. Grande parte do lixo urbano não é coletado encontrando-se em largadouros públicos e em terrenos baldios. Do lixo coletado só uma pequena parcela é disposta adequadamente e uma e uma significativa de $76 \%$ é disposta inadequadamente a céu aberto ou vazadouros em áreas alagadas. Consequentemente, os mananciais (rio, ribeirão, lago, lagoa) que bastecem 2641 cidades já apresentam alguma forma de contaminação (IBGE, 1992).

- Entre 25 e $60 \%$ da água tratada são perdidas nas redes de distribuição. Grande parte desse desperdício é consequência da cultura da abundância, pelo obsoletismo dos equipamentos e pelo absolutismo nas empresas (ALDO,1996).

Um caso bastante preocupante, é o desperdício de água na agricultura. $\mathrm{O}$ uso de métodos de irrigação de superfície, como, espalhamento, pivô central, aspersão convencional e similares, cuja a eficiência é somente de 30\% em 90\% dos casos (FAO, 1988). 
“A importância da tarefa se impõe pelas consequências socioeconômicas óbvias - decorrentes do uso racional dessa riqueza - e pelas implicações ambientais e de mercado, cujo alcance é mundial" (ALDO,1996).

\subsection{Possíveis Soluções}

Segundo Carey (1993), a sustentabilidade hídrica corresponde "ao número máximo de usuários e demandas associadas que determinado ambiente pode prover de forma permanente". Por isso, ao usar e desenvolver os recursos hídricos de uma determinada área é primordial priorizar a satisfação de necessidades básicas e de proteção dos ecossistemas.

Os recursos hídricos é um insumo básico indispensável ao desenvolvimento econômico. Assim os usuários da água são tarifados, porque segundo as regras do atual comércio global, a não cobrança dessa tarifa, a água o mundo à uma situação de dumping ambiental. Assim, a viabilidade do uso da água deve ser definida apenas com base no simples balanço entre oferta física e demanda de água, mas principalmente, em termos econômico-financeiro.

Quando os limites de capacidade são ultrapassados o retorno econômico é quase que nulo. Então, alguns planos de racionalização do uso da água devem ser implementados, como, utilização de da água subterrânea ou de superfície e de outras fontes potenciais - recarga artificial de aquíferos com excedentes de descarga ou de enchentes de rios, excedentes sazonais de estações de tratamento de águas brutas, reuso, distribuição de água de qualidade diferenciada, dentre outras - têm de contar com o apoio de medidas contaminantes de conservação e minimização, dos desperdícios.

Com o aumento da demanda, se faz necessário um melhor gerenciamento. Uma análise foi realizada sobre a situação de cada país formador da Organização das Nações Unidas (ONU) e indicou os seguintes resultados (FALKENMARK \& LINDH,1976):

- Quando a demanda de água representa menos de 5\% dos seus potenciais de águas renováveis (componente de fluxo superficial + subterrâneo), pouca atividade de gerenciamento é necessária. A água nesse caso, pode ser considerada como um bem livre; 
- Entre 5 e $10 \%$, se faz necessário um gerenciamento apenas de um gerenciamento e um pequeno investimento para solucionar alguns possíveis conflitos locais;

- Quando o percentual fica entre 10 e 20\%, o gerenciamento torna-se indispensável e há uma necessidade de investimentos médios;

- Quando a porcentagem ultrapasso aos $20 \%$, a situação torna-se crítica e é exigido um gerenciamento e investimento intensivos.

A tabela 1 abaixo, fornece dados sobre a disponibilidade hídrica social nos rios, dando enfoque especificamente na última coluna da direita, foram calculados tendo como base as demandas das Unidades Planejamento (UP's), atuais e projetadas para o ano de 2020, sendo não contabilizada as reservas de águas subterrâneas.

Isso significa que a disponibilidade da água subterrânea a medida que não sofre os efeitos do período de seca poderá ter a função de abastecimento. Assim sendo, os aquíferos terão a função de estocar excedentes de água das enchentes dos rios, protegendo dos processos de evaporação/evaporação, para regularizar a oferta de água nos períodos de seca.

Se faz necessário a aplicação de modelos de gerenciamento integrado ambiental e dos recursos hídricos superficiais e subterrâneos e dos conceitos de uso e proteção, do usuário pagador, do poluidor pagador e outros fatores que devem estar presentes nos planos estaduais.

Analisado especificamente a Bacia do Rio São Francisco, que apresenta um índice de $23 \%$, assim sendo necessário um de urgente gerenciamento intensivo, principalmente quando atingir 34\% no ano de 2020.

Assim, para que a transposição do rio São Francisco chegue a alcançar a condição de instrumento de redução do nível de pobreza da maioria da população do Nordeste e de efetivo enfrentamento da seca, torna-se necessário, além de obedecer a parâmetros técnicos de perenização da oferta de água no semiárido, incluir-se uma proposta política de gerenciamento regional das águas e organização da coletividade. Tudo de acordo com a Constituição Federal de 1988 (relativa ao domínio hídrico) e da Lei de 9433 de 1997, que institui a Política Nacional de Recursos Hídricos (ALDO, 1996). 


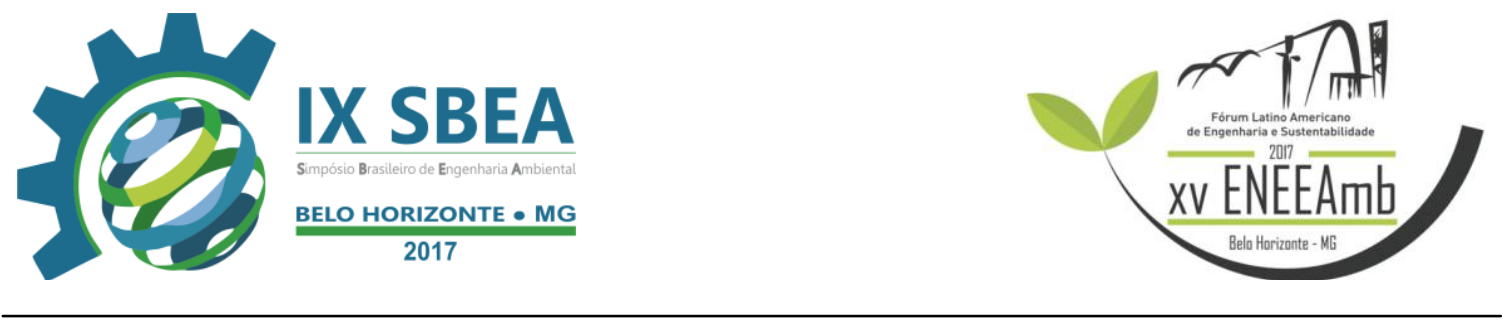

O cenário da crise da água no nordeste brasileiro, não é refletida somente nos dias atuais, mas também é algo para o futuro, e algumas medidas devem ser tomadas. No longo prazo deve-se priorizar ações de acordo com propostas baseadas no capítulo 18 da Agenda 21 - Rio 92, alguns passos importantes:

- No plano governamental, seria, ações bem planejadas destituídas de clientelismo para motivar a participação da sociedade organizada. Essas ações devem ser proativas, antecipando-se à existência do problema e procurando evitá-lo e/ ou neutralizá-lo;

- Sempre promover o desenvolvimento do capital humano e trabalhar ativamente com a sociedade organizada e tentando reconhecer nela o ideal interlocutor para o enfrentamento da crise da água em benefícios dos interesses gerais;

- Organizar ações para que a cidadania pelas águas se efetuem sem superposição e sem conflitos de orientação. Deve-se estabelecer uma noção mínima de democrática de disponibilidade à população. 


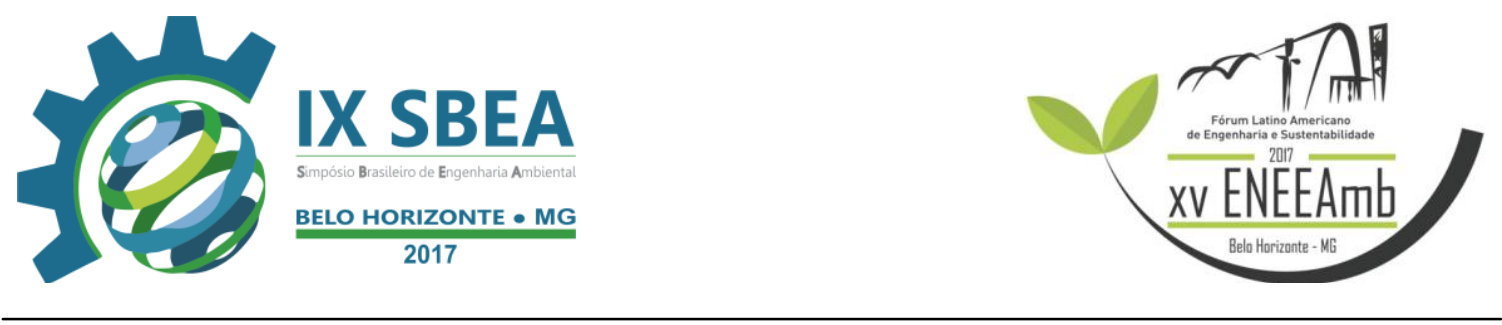

Tabela 1: Disponibilidade hídrica social nos rios, necessidade de gerenciamento no Nordeste do Brasil c situação comparativa de Isracl (Rebouças, 1996)

\begin{tabular}{|c|c|c|c|c|c|}
\hline $\begin{array}{l}\text { UPs - Unidades } \\
\text { Plancjamento }\end{array}$ & $\begin{array}{l}\text { Área } \\
\mathrm{Km}^{2}\end{array}$ & $\begin{array}{l}\text { *Q médio dos } \\
\text { rios sup+subt) } \\
\times 10^{6} \mathrm{~m}^{3} / \text { ano }\end{array}$ & $\begin{array}{l}\text { Popul. urb+rural } \\
\text { (IBGE, 1991) }\end{array}$ & $\begin{array}{l}\text { Disponib. } \\
\mathrm{m}^{3} / \mathrm{hab} / \mathrm{a}\end{array}$ & $\begin{array}{l}* * * \% \text { Demanda } \\
\text { Total/vazĩo } \\
\text { média dos rios }\end{array}$ \\
\hline 1. Tocantins-Maranhão & 32900 & $5450+500$ & $264818+184556$ & 13000 & $2-3$ \\
\hline 2. Gurupi & 50600 & $15290+2510$ & $192304+386480$ & 30754 & $2-2$ \\
\hline 3. Mearim-Grajaú-Pindaré & 97000 & $14140+3430$ & $842469+1479103$ & 7568 & $3-4$ \\
\hline 4. Itapecuru & 54000 & $7750+1550$ & $326331+445288$ & 12052 & $3-3$ \\
\hline 5. Munim-Barreirinhas & 27700 & $5690+3120$ & $121818+293939$ & 21190 & $2-3$ \\
\hline 6. Parnaíba & 330000 & $31090+9030$ & $1741594+1617872$ & 11942 & $5 \cdot 7$ \\
\hline 7. Acaraú-Coreaú & 30500 & $3910+1360$ ) & $426746+473672$ & 5853 & $4-6$ \\
\hline 8. Curu & 11500 & $2010+350$ & $192629+192533$ & 6127 & $10 \cdot 13$ \\
\hline 9. Fortaleza & 14700 & $1740+530$ & $2411212+270894$ & 846 & $28-40$ \\
\hline 10. Jaguaribe & 72000 & $3340+810$ & $975770+992114$ & 3805 & $23-34$ \\
\hline 11. Apodi-Mossoró & 15900 & $520+300$ & $368004+223712$ & 1386 & $16-27$ \\
\hline 12. Piranhas- Açu & 44100 & $2130+590$ & $684734+560677$ & 2184 & $17-24$ \\
\hline 13. Leste Potiguar & 24440 & $950+730$ & $1145863+539203$ & 997 & $22-34$ \\
\hline 14. Leste Paraíba & 23760 & $1290+900$ & $1519834+05283$ & 1030 & $21-30$ \\
\hline 15. Leste Pernambuco & 25300 & $3380+950$ & $4170296+1118349$ & 819 & $44-70$ \\
\hline 16. Bacias Alagoas & 17100 & $1430+1650$ & $1253953+707524$ & 1570 & $27-51$ \\
\hline 17. Sào Francisco & 487000 & $24400+16700$ & $3184912+3253205$ & 6384 & 23-34 \\
\hline 18. Vaza-Barris & 22330 & $810+390$ & $755592+263655$ & 1177 & $16-28$ \\
\hline 19. Itapicuru-Real & 46100 & $1200+880$ & $517118+892025$ & 1476 & $11-19$ \\
\hline 20. Paraguaçu-Salvador & 81560 & $4215+4205$ & $3480425+1233761$ & 1786 & $13-22$ \\
\hline 21. Contas- Jequié & 62240 & $4860+700$ & $612371+807498$ & 3916 & $12-25$ \\
\hline 22. Pardo-Cachocira & 42000 & $5920+1240$ & $909008+475229$ & 5172 & $4-6$ \\
\hline 23. Jequitinhonha & 23200 & $5570+540$ & $107416+116769$ & 27254 & $1-2$ \\
\hline 24. Extremo Sul da Bahía & 27300 & $1540+5440$ & $305793+190127$ & 14075 & $5-9$ \\
\hline NORDESTE (SUDENE) & 1663230 & $\begin{array}{c}148625+58405 \\
(207030)\end{array}$ & $\begin{array}{c}26511010+17323468 \\
(43834478)\end{array}$ & 4723 & $11-16$ \\
\hline Isracl $^{\star *}$ & 20330 & 1.700 & 4.600 .000 & 370 & $* * * * 120-?$ \\
\hline
\end{tabular}

Fontes: * PLIRHINE (SUDENE, 1980); ** World Resources Institute (1991); ${ }^{* * *}$ Demandas de $1990 \mathrm{e}$ do ano 2020

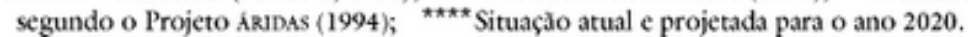

\section{CONCLUSÕES/RECOMENDAÇÕES}

A região Nordeste brasileira, desde os primórdios do período colonial, tem como a seca a ideia central de referência, a qual deve ser fortemente combatida. Outra ideia já imposta é ao que se refere à baixa produtividade por consequência da sua característica de semiárido. Mas a realidade é o contrário. Exemplos demonstram que apesar de certas limitações naturais, até o semiárido possuem um conjunto de peculiaridades e potencialidades, que as quais forem bem administradas, podem levar a região a um 
desenvolvimento capaz de elevar a qualidade de vida da população. Por influência da pressão da sociedade e da globalização da economia, a cidadania pelas águas da região nordeste, faz-se uma parte importante na urgente mudança que se deve se processar na cultura organizacional do Estado, da sociedade, das empresas e, geral.

Essas mudanças tem uma grande influência para o desenvolvimento de novos valores que ajudem a organizações públicas, privadas e os indivíduos a enfrentar as realidades sociais, ambientais e de desenvolvimento que se encontram em rápida transformação. Assim ficando fácil acesso de se desenvolver uma convivência normal e criativa com a seca, gerando iniciativas que potenciem hábitos coletivos de captação e uso mais eficiente da água disponível, e ações preventivas para tempos mais duros. A sociedade precisa ter consciência e apoiar essas ações, e conhecer quais são suas prioridades e como elas se inserem num plano de conjunto que se desdobra ao longo do tempo. Só assim então se pode ter a cidadania pelas águas, que é proposto da manipulação.

\section{REFERÊNCIAS BIBLIOGRÁFICAS}

ALMIR C. José; MONTENEGRO M.G.L, Suzana; B. CAMPOS, José Nilson. A Questão Da Água No Semiárido Brasileiro. Capítulo. 5. p.81 RESUMO S.n.t.

AGÊNCIA NACIONAL DE ÁGUAS - ANA. Conjuntura dos Recursos Hídrico no Brasil: regiões hidrográficas brasileiras, Brasília -DF, 2015.

C. REBOUÇAS, Aldo, Água na região Nordeste: desperdício e escassez, São Paulo, Estud. av. vol.11 no.29 Jan./Apr. 1997 Disponível em: <http://www.scielo.br/scielo.php?pid=S010340141997000100007\&script=sci_arttext\&t $\operatorname{lng}=\mathrm{pt} / \mathrm{>}$. Acesso em: 04 jun. 2015.

CHRISTOFIDIS, D. A água e a crise alimentar. Disponível em: < www.iica.org.br/Aguatrab/Demetrios\%20Christofidis/P2TB01.htm< 1997 14p. Acesso em: 07 jun. 2015.

FIBGE - Fundação Instituto Brasileiro de Geografia E Estatística 1991. Censo Demográfico 1991. Resultados do Universo Relativo às Características da População e dos Domicílios. FIBGE, Rio de Janeiro.

INSTITUTO BRASILEIRO DE GEOGRAFIA E ESTATÍSTICA (IBGE), Boletim Geográfico, Rio de Janeiro, no.196 - ano 26- jan./fev. 1997. 
KI-MOON, BAN Ban Ki-moon depoimento [out. 2014]. Depoimento concedido na abertura da Cimeira sobre a água, Budapeste na Hungria.

MARENGO, J.A. Água e Mudanças Climáticas Estudos Avançados. 22 (63), 2008

MINISTÉRIO DA INTEGRAÇÃO NACIONAL. Plano de Desenvolvimento Sustentável da Região Turística do Meio-Norte. (Brasília-DF) Junho / 2012

MINISTÉRIO DO DESENVOLVIMENTO AGRÁRIO (Alagoas). Plano Territorial de Desenvolvimento Rural Sustentável do Agreste de Alagoas, 2011.

MINISTÉRIO DO MEIO AMBIENTE, Brasília-DF. A Questão da água no Nordeste, 2012.

NACIB A., Aziz, Sertões e sertanejos: uma geografia humana sofrida Dossiê Nordeste Seco, São Paulo, vol.13 no.36 Maio/Agosto 1999 Disponível em < http://www.scielo.br/scielo.php?pid=S010340141999000200002\&script=sci_arttext\&tl ng=es $>$ Acesso em: 06 jun. 2015

VOSTI, S.A.; REARDON, T. Desarrollo agricola, sostentabilidad y alivio de la pobreza: el triangulo critico. Rede Internacional de Metodologia de Investigación de Sistemas de Producción. Disponível em < www.rimisp.cl/r/rearvos.htm. 1999> Acesso em: 07 jun 2015 